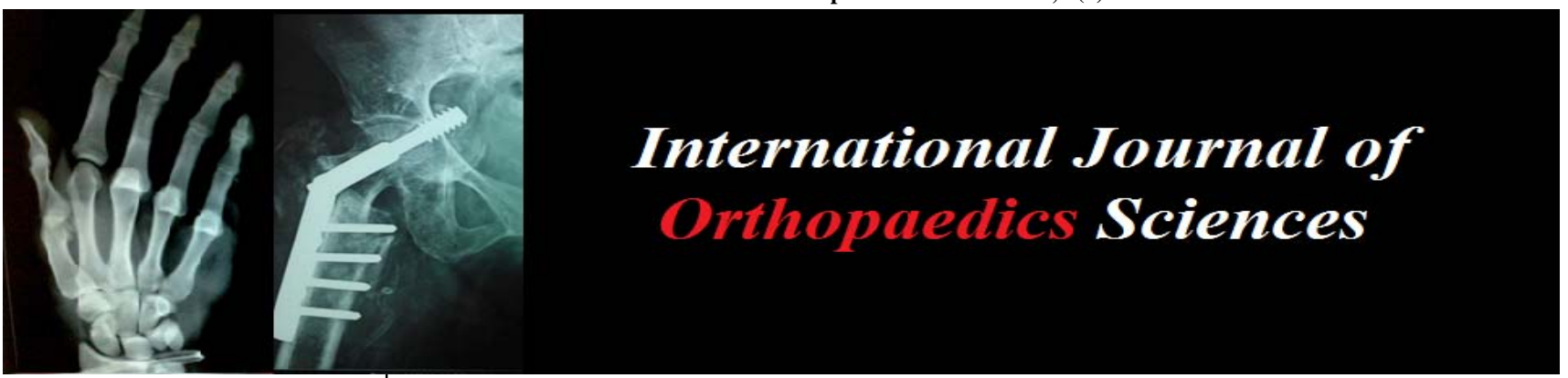

E-ISSN: 2395-1958

P-ISSN: 2706-6630

IJOS 2020; 6(2): 941-955

(C) 2020 IJOS

www.orthopaper.com

Received: 22-02-2020

Accepted: 25-03-2020

Dr. Vellanki Sarath

M.S. (Orth), Associate Professor,

Katuri Medical College and

Hospital, Chinakondrupadu,

Guntur, Andhra Pradesh, India

Dr. A Srinivasa Rao

Professor \& HOD, Katuri

Medical College And Hospital,

Chinakondrupadu, Guntur,

Andhra Pradesh, India

Dr. Ch Prathyush

M.S. (Orth), Katuri Medical

College and Hospital,

Chinakondrupadu, Guntur,

Andhra Pradesh, India
Corresponding Author: Dr. Vellanki Sarath M.S. (Orth), Associate Professor, Katuri Medical College and Hospital, Chinakondrupadu, Guntur, Andhra Pradesh, India

\section{A study of intra articular platelet rich Plasma therapy in the treatment of knee Osteoarthritis}

\author{
Vellanki Sarath, A Srinivasa Rao and Ch Prathyush
}

DOI: https://doi.org/10.22271/ortho.2020.v6.i2o.2165

\section{Abstract}

Introduction: Osteoarthritis (OA) represents a failure of the di-arthrodial, synovial lined joint. Among the elderly, knee Osteoarthritis is the leading cause of chronic disability ${ }^{[1]}$. Because of the increased lifespan and obesity the prevalence of osteoarthritis is in the rise in India.

Aim of the Study: Whether platelet rich plasma is useful in OAknee or not.

Objectives: To evaluate the role of Autologous Platelet Rich plasma (APRP) in the treatment of patients presenting with primary osteoarthritis and to analyze whether it could be a cost effective disease modifying measure.

Materials and Methods: Total 100 OA Knee cases are selected from the Katuri Medical College and Hospital, randomly. First 50 were given A PRP injection to the OA Knee, Next 50 were given normal saline.

Platelet-Rich Plasma: Platelets are cytoplasmic fragments of megakaryocytes, that are formed in the marrow ${ }^{[26]}$ and are approximately $2 \mu \mathrm{m}$ in diameter. They contain more than thirty bioactive proteins, of which many of them have a fundamental role in hemostasis or in tissue healing ${ }^{[28]}$. Fundamental protein growth factors which are actively secreted by platelets will initiate all the wound healing process ${ }^{[29]}$ PRP includes three proteins in blood which is known to act as cell adhesion molecules: Fibrin, fibronectin and vitronectin ${ }^{[30]}$.

Discussion: Osteoarthritis is a disorder of synovial joints characterized by focal loss of hyaline cartilage with proliferation of new bone and remodeling of joint contour, mainly due to uncoupling of balance between cartilage regeneration and degeneration. Osteoarthritis is a dynamic repair process of synovial joints that may be triggered a variety of insults. We in our study had randomly chosen 100 patients with classic findings of Osteoarthritis and divided them in to two groups. Both the groups were comparable on baseline characteristics of age, height, weight, BMI, pre injection WOMAC score. Fifty of these patients were administered an intra articular injection of Platelet Rich Plasma and other fifty received Normal Saline.

The Efficacy of Platelet Rich Plasma in reducing pain, stiffness and physical function were assessed and scored on WOMAC index for both study and control group. The Results were analyzed using unpaired ' $t$ ' test and chi- square test. Age distribution revealed mean age in group I to be 53.14 and the mean age in Group II was 53.68.

Outcome Analysis: The study group and the control group are advised to follow up at 6 weeks, 3 months and 6 months. Outcome analysis for the efficacy was done for reduction in pain, reduction in stiffness and improvement in physical function using WOMAC scale. The Patients were also assessed for reduction in pain using Visual analog scale both at pre injection and at 6 months post injection.

Conclusion: Our study has thrown up an interesting choice of treatment modality using Platelet Rich Plasma in the treatment of Knee Osteoarthritis and it has proved efficacious in the observation period of six months.

Keywords: Osteoarthritis (OA), Platelet Rich Plasma (PRP)

\section{Introduction}

Osteoarthritis is age related, affecting more than $80 \%$ of people over the age of 55 . OA in weight-bearing joints is strongly linked to body mass index. As life expectancy increases, and the rate of obesity reaches epidemic proportions, OA has become increasingly common. The pathogenesis involves an imbalance between normal cartilage derivative and repair mechanisms, which results in net cartilage loss, hypertrophy of bone, and osseous outgrowths called osteophytes. 
OA has a predilection for finger joints, knees, hips, shoulders, and the spine. Occurrence in an atypical joint, such as an elbow, can usually be traced to prior trauma, a congenital joint abnormality, underlying systemic disease, or a chronic crystalline arthropathy. The heterogeneity of OA arises from the many factors that can contribute to cartilage damage. Using PRP injections into OA knees.

\section{Materials and Methods Study Design}

Randomized controlled trial. The patients were subjected to a standardized injection protocol and were assessed on variable such as pain, stiffness and physical function using WOMAC scale and for pain using visual analog scale at pre injection, 6 weeks post injection, 3 months and 6 months post injection.

\section{Methods}

The patients attending the OPD of Orthopaedics Department at with complaints of bilateral knee pain were screened and those diagnosed as bilateral or unilateral Knee Osteoarthritis were chosen for the study.

The Patients, classified either grade 0 to 4 on the KellgrenLawrence grading scale or grade 1 to 4 on the Ahlback scale, were included in the study after prior well informed written consent. Hundred Patients were chosen and randomly divided into two groups of fifty each. Group I received intra articular injection Platelet Rich Plasma in to knee served as study group. Group II received normal saline and served as control. Randomization ensured that both the groups were comparable with respect to age, sex, height, weight, body mass index and pre injection WOMAC score.

\section{Platelet-Rich Plasma}

Platelets are cytoplasmic fragments of megakaryocytes, that are formed in the marrow ${ }^{[26,27]}$ and are approximately $2 \mu \mathrm{m}$ in diameter. They contain more than thirty bioactive proteins, of which many of them have a fundamental role in hemostasis or in tissue healing ${ }^{[28]}$. Fundamental protein growth factors which are actively secreted by platelets will initiate all the wound healing process ${ }^{[29]}$ PRP includes three proteins in blood which is known to act as cell adhesion molecules: Fibrin, fibronectin and vitronectin ${ }^{[30]}$. Activation of these causes the granules that are present in platelets to fuse to their cell membrane (also called degranulation) from where the secretory proteins (e.g. PDGF, TGF- $\beta$ etc.) [31]. were transformed to a bioactive state by addition of histones and carbohydrate side chains ${ }^{[28]}$. These active proteins which are then secreted are, binded to transmembrane receptors of target cells, they include mesenchymal stem cells, osteoblasts, fibroblasts, endothelial cells and epidermal cells. These agonists bind transmembrane receptors which then activates an intracellular signal protein which causes the expression of the gene sequence which directs cellular proliferation, matrix formation, osteoid production, collagen synthesis etc. Thus provoking tissue repair mechanism and tissue regeneration ${ }^{[28,}$ 33]. The active secretions of the growth factors by platelets begins within ten minutes of activation, with $>95 \%$ of the presynthesized growth factors secreted within the 1sthour [34]. Marx proposed platelet count of $10 \mathrm{lakh} / \mathrm{ml}$ in $5 \mathrm{~mL}$ of PRP, as a working definition of PRP, which was based on the scientific proof of bone and soft tissue healing enhancement [34]. There was a scarcity of studies for stating the amount of concentration at which optimal stimulation of platelets occurs. Rughetti et al. ${ }^{[35]}$ has studied the relationship between the amount of concentration of platelets in a platelet gel and its changes that it causes in the functional activity in human endothelial cells. The proliferation of endothelial cells and its migration and invasion of endothelial cells has been observed to occurred in a bellshaped manner. The authors found the stimulation for proliferation of endothelial cells was peaked at $1.25 \times 10$ and angiogenesis occurs at $1.5 \times 10$ platelets $/ \mathrm{mL}$, respectively. Thus it signifies the fact about PRP platelet count of $1 \mathrm{million} / \mathrm{mL}$ become the working definition of therapeutic PRP and it also reasons out criticism of not getting the expected best results of PRP, which might be due to lower concentrations of platelets.

\section{Classification}

In the literature on PRP it is considerable, but the results published are contradictory. It is very difficult to sort and to interpret the available data, due to availability of a large number of preparation techniques, and terminologies, of these materials, and the endless list of their potential applications. The classification proposed by Ehrenfest et al. (2009), described four main families of preparations that can be defined, depending on their cell content and fibrin architecture ${ }^{[36]}$.

1. Pure Platelet Rich Plasma (P-PRP) or leucocyte poor PRP products are the preparations that are without leucocytes and that of a low density fibrin network after activation.

2. Leucocyte PRP (L-PRP) are the products that are preparations with leucocytes and that with a low-density fibrin networks after their activation. It is in this family largest number of commercial or experimental systems are performed. Particularly, many automated protocols have been developed which use the specific kits which allows minimum handling of the blood samples and maximum standardization of the preparations.

3. Pure platelet rich fibrin (PPRF) or leucocyte-poor platelet-rich fibrin

preparations are those without leucocytes and those with a high density of fibrin network. These products exists in a strongly activated gel form, and cannot be injected or used like traditional fibrin glues.

3. Leucocyte and platelet rich fibrin (LPRF) or secondgeneration PRP

products are the preparations with leucocytes and those with a high density of fibrin network.

This classification system was largely cited, advocated, and validated by a multi-disciplinary conference published in $2012^{\text {[37]. }}$

\section{Preparation of PRP}

PRP is obtained from the sample of blood drawn at the time of treatment from patient. $30 \mathrm{cc}$ of venous blood drawn can yield upto 3-5 cc of PRP depending on the platelet count of that individual, and depending on the device used, and the technique employed at the time of preparation. The blood drawn is transferred into anticoagulant tube, such as citrate dextrose to prevent platelet activation prior to its use. we employed a specialized 'table top cold centrifuge' device. Preparation related costs are significantly lower than with commercial kit.

\section{Principles of PRP Preparation}

PRP is prepared by the process known as differential centrifugation. In differential centrifugation, acceleration force is adjusted to sediment cellular constituents based on their different specific gravity. There are many ways to 
prepare PRP. Most commonly it is prepared by the PRP method or by the buffy-coat method. In the PRP method, an initial centrifugation is done to separate red blood cells (RBC) and it is followed by a second centrifugation to get concentrate platelets, which will be suspended in the smallest final plasma volume. WB (whole blood) is initially collected in tubes that contain anticoagulants. The first spin is performed at constant acceleration which will separate RBCs from the remaining WB volume. After the first spin, the WB separates into three layers: an upper layer that contains mostly platelets and WBC, an intermediate thin layer that is known as the buffy coat and that will be rich in WBCs, and a bottom layer that consists mostly of RBCs. For the production of pure PRP (P-PRP), upper layer and superficial buffy coat are transferred to an empty sterile tube. For the production of leucocyte rich PRP (L-PRP), the entire layer of buffy coat and few RBCs are transferred. The second spin is then performed. For the second spin it should be just adequate to aid in formation of soft pellets (erythrocyte-platelet) at the bottom of the tube.

The upper portion of the volume that is composed mostly of PPP (plateletpoor plasma) is removed. Pellets are

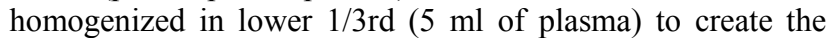
PRP (Platelet-Rich Plasma). In the buffy coat method (used in this study), whole blood (WB) is centrifuged at a 'high speed' with subsequent collection of the buffy coat. A buffy coat contains high concentration of leucocytes ${ }^{[38,39]}$. From small volume of WB $(10 \mathrm{~mL})$, a very thin layer of a buffy coat can be produced. The difficulty lies in separating this thin buffy coat layer that contains mainly white blood cells (WBCs) and platelets, from the underlying $\mathrm{RBC}$ layer.

1. WB should be stored at $20{ }^{\circ} \mathrm{C}$ to $24{ }^{\circ} \mathrm{C}$ before centrifugation.

2. Centrifuge WB at a 'high' speed.

3. Three layers are formed because of its density: The bottom layer consisting of RBCs, the middle layer consisting of platelets and WBCs and the top PPP layer.

4. Remove supernatant plasma from the top of the container.

5. Transfer the buffy-coat layer to another sterile tube

6. Centrifuge at low speed to separate WBCs or use leucocyte filtration filter.

\section{Comparison of Studies of Preparation}

$\mathrm{PRP}$ is prepared by centrifugation varying the relative centrifugal force, temperature and time. It has been seen that the two-step procedure renders the highest output. Preparation procedures are also relevant, as shown by studies of the chondro-inductive and steoinductive potential of PRP [40]. There are numerous protocols in the current literature that describe the optimal conditions for centrifugation However, these various protocols have been optimized with respect to different variables of the process, such as volume and sampling of processed WB, number of spins, time period of centrifugation, and range of centrifugal acceleration. Considering the complexity of an autologous product such as PRP and the need for quality control in clinical applications, it is crucial to demonstrate procedure's ability to reproduce consistent results.

Kahn et al. ${ }^{[41]}$ Determined that a centrifugal acceleration of $3731 \times \mathrm{g}$ for a period of $4 \mathrm{~min}$ was the optimal condition for obtaining the highest platelet concentration from $478 \mathrm{~mL}$ of WB. The highest platelet recovery efficiency obtained by Slichter and Harker ${ }^{[42]}$ was $80 \%$, using a sample of $250-450$ $\mathrm{mL}$ of $\mathrm{WB}$ centrifuged at $1000 \times \mathrm{g}$ for a period of $9 \mathrm{~min}$. It was observed that a subsequent centrifugation step of $3000 \times \mathrm{g}$ for a period of 20 min decreased the platelet viability. Landesberg et al. obtained PRP samples that had approximately 3.2 times the concentration of the WB baseline. The centrifugation procedure processed $5 \mathrm{~mL}$ of $\mathrm{WB}$ for two spins at $200 \times \mathrm{g}$ for 10 min per spin ${ }^{[43]}$.

Jo et al. examined the effect of the centrifugation time and gravitational force $(\mathrm{g})$ on the platelet recovery ratio of PRP. Two-step centrifugations for preparing PRP were used in 39 subjects. WB was centrifuged from $500 \times \mathrm{g}$ to $1900 \times \mathrm{g}$ at $200 \times \mathrm{g}$ increments for $5 \mathrm{~min}$ and from $100 \times \mathrm{g}$ to $1300 \times \mathrm{g}$ at $200 \times \mathrm{g}$ Bausset et al. found that a centrifugation of $130 \times \mathrm{g}$ or $250 \times \mathrm{g}$ for a period of $15 \mathrm{~min}$ was optimal when performing a procedure that involved two spins. A platelet concentration factor of 3.47 was obtained from the $8.5 \mathrm{~mL}$ WB processed, and $2.0 \mathrm{~mL}$ of plasma was processed in the second spin step [44].

Tamimi et al. ${ }^{[45]}$ compared two methods for obtaining PRP: Double centrifugation (ACE system; Surgical Supply and Surgical Science Systems, Brockton, MA, USA) and single centrifugation (Nahita System; Nahita, Navarra, Spain). Three test tubes of $8.5 \mathrm{~mL}$ WB each were introduced into an ACE centrifuge machine and subjected to a force of $160 \times \mathrm{g}(1300$ $\mathrm{rpm}$ ) for $10 \mathrm{~min}$. For second centrifugation, $400 \times \mathrm{g}$ force (2000 rpm) for $10 \mathrm{~min}$ was applied. For Nahita system blood was extracted into $3.5-\mathrm{mL}$ citrated tubes (Venojet; Terumo MR, Tokyo, Japan) containing $0.5 \mathrm{~mL}$ of trisodium citrate, citrate, and ACD as anticoagulants. Test tubes were centrifuged with a $280 \times \mathrm{g}$ force $(1500 \mathrm{rpm})$ for $7 \mathrm{~min}$. Platelet concentration from the ACE and Nahita systems were (336\%) and $(227 \%)$, respectively. Mazzocca et al. ${ }^{[46]}$ analyzed three protocols for preparing PRP samples with different compositions: A low platelet $(382 \times 10 / \mathrm{mm})$ and low WBC $(0.6 \times 10 / \mathrm{mm})$ process with one spin step at 1500 rpm for 5 min $(10 \mathrm{~mL} \mathrm{WB})$; a high platelet $(940 \times 103 / \mathrm{mm})$ and high WBC $(17 \times 103 / \mathrm{mm})$ process with one spin step at $3200 \mathrm{rpm}$ for $15 \mathrm{~min}(27 \mathrm{~mL} \mathrm{WB})$; and a double-spin process $(1500 \mathrm{rpm}$ for $5 \mathrm{~min}$ and $6300 \mathrm{rpm}$ for $20 \mathrm{~min}$ ) that produced a higher platelet concentration $(472 \times 103 / \mathrm{mm})$ and lower WBC $(1.5$ $\times 103 / \mathrm{mm})$.

Anitua et al. ${ }^{[47]}$ used only one centrifugation spin step and collected the volume immediately above the erythrocyte layer. Blood was collected on sterile tubes $(4.5 \mathrm{~mL})$ containing $3.8 \%(\mathrm{w} / \mathrm{v})$ trisodium citrate, then centrifuged at $460 \times \mathrm{g}$ for 8 min (PRGF System1, B.T.I. Biotechnology Institute, VitoriaGasteiz, Spain). This protocol obtained a platelet concentration factor of 2.67 above the baseline value. In this study we modified Mazzocca et al method for the preparation of the PRP.

\section{Selection of the patients for surgery Inclusion criteria}

- $\quad$ patients with knee OA K-L Score 2 or more;

- $\quad$ with pain greater than 3 on VAS Scale;

- $\quad$ older than 18 years of age;

- Who have failed any other conservative treatment (analgesics, NSAIDs, steroidal/ hyaluronic acid/Ozone injections, visco supplementation and/or physical medicine); unwilling or not available for knee arthroplasty replacement.

\section{Exclusion Criteria}

Immuno suppressed patients

Patients with secondary osteoarthritis

Patients with connective tissue disorders 
Patients with inflammatory disorder of joints

Patients who have received steroid injections within past 6months

Patients with hemoglobin less than $10 \mathrm{mg} \%$

Patients with tumors, metabolic diseases of bone

Patients with coexisting backache

Injection Protocol: ${ }^{[73,74]}$

The Injection procedure was performed in operation theatre. The Patient was placed supine on the operation table. Parts painted and draped. Under sterile aseptic precautions $5 \mathrm{ml}$ of Platelet Rich Plasma was injected into the joint cavity from medial approach with knee in 45 degree of flexion \& sterile bandaging given. The Patient is advised

bed rest for 1day. The Patient is advised to avoid NSAIDS for 2 days before and after

injection. Paracetamol injection doses of 500mg is allowed in cases of febrile illness or discomfort due to pain. In the control group, $5 \mathrm{ml}$ of Normal Saline is injected in to the knee of the patients. The Patients are advised to carry on with their regular routine work from Day 2.

\section{Discussion}

Osteoarthritis is a disorder of synovial joints characterized by focal loss of hyaline cartilage with proliferation of new bone and remodeling of joint contour, mainly due to uncoupling of balance between cartilage regeneration and degeneration. Osteoarthritis is a dynamic repair process of synovial joints that may be triggered a variety of insults.

We in our study had randomly chosen 100 patients with classic findings of Osteoarthritis and divided them in to two groups. Both the groups were comparable on baseline characteristics of age, height, weight, BMI, pre injection WOMAC score. Fifty of these patients were administered an intra articular injection of Platelet Rich Plasma and other fifty received Normal Saline. The Efficacy of Platelet Rich Plasma in reducing pain, stiffness and physical function were assessed and scored on WOMAC index for both study and control group. The Results were analyzed using unpaired test and chi- square test. Age distribution revealed mean age in group I to be 53.14 and the mean age in Group II was 53.68.

The p-value derived using unpaired t-test is 0.6885 , rendering age factor insignificant. Gender distributions were comparable on both groups with $80 \%$ being male $20 \%$ being female. The p-valve using chi square test is 0.000 . The Gender factor was in significant.

The mean height in group I was 159.66 and the mean height in Group II was 159.68. The p-valve using unpaired t test turned insignificant (0.9895).

The mean weight, in group I was 68.62 and group II was 67.66 with pvalve of 0.4777 (insignificant).

The mean BMI was 26.97 in group I and 26.64 in Group II. The p-valve is 0.5507 (insignificant).

Thus the study ensured that all patients were comparable on baseline characters.

The Global WOMAC showed a mean of 74.2 at pre injection period which decreased to 62.46 at 6 weeks follow up and 47.68 at 3 months and declining to 33.40 at 6 months.

The study showed a significant decrease in global WOMAC score, which was also consistent throughout the study period. The Individual variables such as pain, stiffness and physical function were assessed. Mean score for pain showed a decrease from 16.58 to 11.32 at 6 weeks post injection. At the end of 6 months follow up, the mean was5.34.

The mean score for pain in group II showed a marginal decreased from 16.30 to 13.74 at 6 weeks but returned to 15.46 at 6 months follow up.

The p-value using unpaired t-test showed significant improvement. Secondary variable stiffness showed significance difference at 3 months follow up and 6 months follow up.

The mean of Physical function decreased from a pre injection score of52.12 to 24.62 at 6 months follow up in Group I.

Group II showed a marginal dip in mean scores from 48.30 to 45.80 and to 44.38 at 3 months The scores leveled at 46.20 at the end of 6 monthsVisual analog score showed a decrease in mean of 7.22 to 3.06 which denoted a change of patient's perception of pain from intense, dreadful, horrible pain to mild annoying pain in Group I.

Group II showed a marginal dip from 6.86 to 4.98 on mean, showing insignificant change in pain.

In study the most frequent grade of knee OA according to K$\mathrm{L}$ scale was $3^{\circ}$ grade $(59.2 \%)$ followed by $4^{\circ}(25.9 \%)$ and $2^{\circ}(14.9 \%)$. This finding is in accordance with other 4 studies from the meta-analysis of Meheaux, ${ }^{[77]}$ where $2^{\circ}(40.7 \%)$ and $3^{\circ}$ grades $(37.9 \%)$ were the most frequent OA grades, followed by $4^{\circ}(12.6 \%)$ and $1^{\circ}(8.7 \%)$.In the same study, Filardo et al. ${ }^{[78]}$ reported only average severity of knee OA; where $2^{\circ}$ grade was again the most frequent.

Similarly, the meta-analysis from Kanchanatawan, mainly considers only patients on $1^{\circ}$ and $2^{\circ} \mathrm{K}-\mathrm{L}$ grades. Most of the studies from Dai's meta-analysis considered for treatment $1^{\circ}$ $3^{\circ} \mathrm{K}-\mathrm{L}$ grades, and only some of them (Gomeli'sl and Sanchez') ${ }^{[80]}$ treated patients with severe OA (K-L $4^{\circ}$ grade). This analysis is very important because most of Randomized Control Trials have demonstrated effectiveness of PRP in decreasing pain and recovering function especially for younger patients and milder knee OA, but there is only one study that showed benefit of PRP even for $3^{\circ}$ grade in knee OA. Our study contributes to show the efficacy of PRP even in patients with $\mathrm{K}-\mathrm{L} 4^{\circ}$ grade.

In our study, a PRP injections has shown effectiveness in improving pain relief, function and rigidity in knee OA patients globally and in all grades of knee OA severity. This is in accordance with most present studies that show moderate quality of evidence supporting the use of PRP on knee OA treatment.

PRP is capable to improve pain and function measured by VAS and WOMAC. But, when it comes to see whether PRP is effective in all grades of severity, is still a matter of controversy.

$\mathrm{Wu}$ et al ${ }^{[81]}$ states that most of trials suggest the efficacy of PRP to improve functional outcomes only for mild knee OA. Spaková concluded that autologous PRP is effective and safe in early knee OA (K-L $1^{\circ}, 2^{\circ}$ and $3^{\circ}$ grades) ${ }^{[82]}$. Moreover, Zlotnicki et al ${ }^{[83]}$ state that multiple studies suggest that advanced knee OA implies ineffective response to PRP injection therapy ${ }^{[83]}$.

Forogh et al. ${ }^{[84]}$ sustain that some studies have reported an inverse relationship between age and response to treatment; in younger patients the outcome was better than those over 50 years. Fernández-Cuadros et al have stated that age is related to knee OA severity and outcomes are dependent on such variable ${ }^{[85,86]}$.

There is only one study that shows benefit on older patients with even $3^{\circ}$ grade knee OA. Our present study shows a clear correlation between age and knee severity and for the first time shows statistical significant improvement of PRPprotocol treatment in all K-L grades, even $4^{\circ}$ grade, to the best of our knowledge. 
There is controversy on PRP processing; therefore, the variability for its clinical responses. However, despite the technique and formulation discrepancies, intra articular PRP injections are effective in degenerative knees. With respect to the number of injections and their frequency, most protocols are different ${ }^{[87]}$. Almost all of them require three injections without any specific reasons or specific justification.

It is believed that the traditional practice of 3 Hyaluronic Acid injections is followed to PRP protocols ${ }^{[88]}$.

In fact, no difference in outcomes for pain and function came from having a single or a double injection of PRP, but both provided superior outcomes compared with saline control.

Görmeli et al. ${ }^{[89,90]}$ compared 3 injections of PRP to one injection of PRP (plus 2 saline injections) or 3 Hyaluronic Acid (HA) injections or 3 saline injections.

Three PRP injections showed better scores in EQ-VAS and IKDC at 6 months compared to one single PRP injection or HA injection. Gobbi et al. ${ }^{[91]}$ showed significant knee OA improvements up to 1 year after PRP injections.

Forogh has stated that one-PRP injection diminished pain for a longer term and improved activities of daily life for a shorttime duration, better than corticosteroids ${ }^{[92]}$. With regard to the quantity of PRP infiltrated, scientist administered volumes that vary from 2 to $8 \mathrm{ml}$, being the most frequent volume $3 \mathrm{ml}$. The same controversy exits with respect to spinning; some authors preferred single spinning, while other prefer double spinning. There is controversy about the necessity to an optimal activation method in clinical practice. By activation, platelets release alpha granules. ${ }^{[93,94]}$

The objective to activate PRP is to ensure that growth factors are immediately available. ${ }^{[33,94]}$

PRP infiltration technique is safe and only small frequencies of adverse effects are reported (mainly infections and allergic reactions)

Pain after injection is greater in PRP when compared to HA infiltration. In our study one out of 50 patients (1.78\%) presented severe pain and inflammation which lead the patient to quit treatment protocol ${ }^{[97]}$.

No other adverse effects were reported on this series. This confirms that PRP treatment is safe.

Despite positive findings and outcome results, most of those results are inconclusive due to low level-evidence studies, diverse PRP protocols and outcome measures ${ }^{[21]}$. The present quasi-experimental before-and-after study, tries to solve such weaknesses, by the use of an stablished protocol, the use of validated outcome measures (VAS and WOMAC Index) and a before-and-after follow-up analysis, all of that gives a good level of evidence, that let us postulate PRP as a promising option for knee OA treatment.

The importance to show our clinical experience in a series of patients is to provide more clinical evidence of an stablished PRP-treatment protocol on knee OA; because, although there is plenty of current meta-analysis, most of them make reference to only 5 to 6 randomized control trials (RCT).

As a resume, activated PRP releases cytokines and growth factors, promoting chondrocyte proliferation and differentiation, modulating inflammation and exerting mesenchymal stem cell proliferation. PRP exerts and antiinflammatory effect by the inhibition of NF- $\kappa \beta$ pathway, but also by a decrease in expressing inflammatory enzymes cyclooxygenase 2 and 4, metalloproteinases and disintegrins. All those combined PRP effects make this treatment as a potential injectable option in the M management of knee OA, improving pain relief and function, as it was demonstrated on this study. In recent study Case control study of 50 patients in
2018 published in JAJS JUNE studied two groups of 25 patients each ${ }^{[98,99]}$.

One group of 25 patients was given therapeutic exercises and Acetaminophen for pain relief (control group). Second group of 25 patients (PRP group) was injected with two courses of intra-articular injection of Leucocyte rich PRP with interval of 6 weeks.

\section{WOMAC}

(Western Ontario and McMaster Universities Osteoarthritis Index) was recorded pre-intervention, at six months \& one year post-intervention in both the groups. Change scores were assessed for statistical significance.

No compilations were noted in both groups and none of the cases needed further surgical intervention during the follow up period. Mean changes of total WOMAC, in PRP group showed significantly better improvement than control group $(P<0.05)$ at all time intervals.

This study showed that intra articular PRP knee injection combined with therapeutic exercise can be more effective in pain reduction and improvement of stiffness and quality of life, compared with therapeutic exercise alone.

Recent study done by the Egyptian rheumatologist work aimed to compare the efficacy of intraarticular injection of PRP therapy in the treatment of KOA. There was a remarkable improvement in the VAS, WOMAC and walking 6 min test in the PRP group after 1 and 3 months. This was in agreement with the results of others who found that PRP resulted in a significantly better WOMAC score from 3 to 12 months post-injection.

Another study showed that the evaluated parameters significantly improved at 24 months compared with those at 12 months, but still better than those at baseline. In another study on Egyptian KOA patients, Hassan et al. reported a highly significant improvement in VAS and functional assessment scores after 6 months. This reduction in pain is due to the capability of PRP to promote the proliferation of chondrocytes, stimulate the production of synovial fluid and limit the inflammatory response. It was reported that intraarticular PRP injection is potent in degenerative knees. Therapy with PRP can potentially adjust the articular inflammatory environment and the progression of OA due to the presence of therapeutic concentrations of interleukin (IL1ra) and transforming growth factor (TGF-b) in PRP. Intraarticular infiltrations with PRP could avert further degeneration of cartilage by retarding OA progression in early stages of the disease.

There was a significant correlation between radiological grades and WOMAC score at baseline and after treatment but as regard to VAS only at the start, while 6- min test there was a negative significant correlation after 1 and 3 months.

These results are in consonance with those of Duymus et al. ${ }^{[100]}$. A meta-analysis emphasized that PRP was effective in mild-moderate grades Chang et al. ${ }^{[101]}$.

PRP injections had a better response in those with low grade $\mathrm{OA}$. It has been reported that better response rates are evident in OA patients treated with PRP injections than in those treated with hyaluronic acid others reported a similar efficacy in elderly patients with advanced KOA who received PRP in association with HA injection and showed pain relief and functional improvement. The follow-up standard weightbearing x-ray images of knees also confirmed the improvement and indicated the regeneration of the articular cartilage.

The treatment strategy of PRP in association with HA 
injection may be useful to treat advanced KOA before these patients receive arthroplasty.

In a randomized trial with patients in the different stages of the disease it is difficult to conclude whether this approach can be applied to a specific phase of cartilage degeneration.

The recent advancement like ozone therapy for OA knee has been started.

In those who received ozone therapy, there was a significant improvement of the studied parameters after 1 month and even more after 3 months. ${ }^{[101]}$ These results coincided with those of many authors who stated that ozone diminishes pain and improves function in KOA.

This short-term effect on symptoms was thought to be due to the relatively potent anti-inflammatory properties of ozone rather than intra-articular structural improvement [101]. Another study of Mishra et al [103], described that the effectiveness lasted 6 months. When, PRP and ozone therapies were compared as regards to VAS and WOMAC score, improvement was achieved with PRP rather than with ozone in the treatment of KOA.

In particular, ozone gas injection was efficient for only the first month, whereas the effect of PRP injection lasted for at least 3 months. Many studies compared PRP and ozone in terms of efficacy ${ }^{[102]}$.

The differences between various studies in the efficacy of ozone therapy in KOA may be related to a number of factors including differences in study populations, severity of disease, and heterogenicity of treatment parameters such as concentration of the ozone, number of settings and different machine design. Use of different outcome measures can also prevent direct comparisons between studies.

There are no unanimous criteria for ozone treatment protocols in KOAincluding number of doses, concentration, volume or frequency ${ }^{[104]}$.

In contrast, no significant difference between PRP and ozone has beenreported ${ }^{[105]}$.

This differences between various studies in the efficacy of PRP due to the application was performed in a single session, other were administered twice at an interval of 2 weeks/month.

Duymus et al. ${ }^{[106]}$ reported in their study that PRP is superior to hyaluronic acid (HA) and ozone in the treatment of mildmoderate KOA and is becoming increasingly widespread.

PRP injection alone was effective for achieving at least 12 months of pain free daily activities. Also, Shen et al. ${ }^{[107]}$ found that intra-articular PRP injections may be more efficacious in the treatment of KOA in terms of pain relief and self-reported function improvement at 3, 6, and 12 months follow-up compared with other injections, including saline placebo, HA, ozone and corticosteroids.

This study confirms that PRP is superior to ozone in the treatment of KOA and is an encouraging treatment option. PRP injection alone was effective for achieving at least 3 months of pain-free daily activity.

This work showed that PRP treatment is safe as no complications as infection or fever occurred.

Patel et al. ${ }^{[108]}$ reported mild complications as nausea and dizziness which were of short duration and these complications were not reported in the current patients.

A larger scale longitudinal study with a longer follow up is recommended to verify the reached results and combining PRP and ozone with rehabilitations programs may reveal the optimum associations of treatment lines for KOA.

In conclusion, that study confirms that PRP is superior to ozone in the treatment of KOA and is an encouraging treatment option. PRP injection alone was effective for achieving at least 3 months of pain-free daily activity.

Alberto Gobbi et al ${ }^{[109,110]}$ randomized study in which 93 patients (119 knees) were followed up for a minimum of 2 years.

Fifty knees were randomly selected prior to the first injection, to receive a second cycle at the completion of 1 year. A cycle consisted of three injections, each given at a monthly interval. The outcome was assessed using Knee Injury and Osteoarthritis Outcome Score (KOOS), Visual Analogue Scale (VAS), Tegner and Marx scoring systems, recorded prior to the first injection and then at 12,18 and 24 months. There was a significant improvement in all scores over time compared to the pre-treatment value $(p<0.001)$.

At 12 months, both groups showed similar and significant improvement. At 18 months, except for KOOS (Symptoms) and Tegner score, all other parameters showed a significant difference between the two groups in favour of the patients who had received the second cycle $(p<0.001)$.

At 2 years, the scores declined in both groups but remained above the pretreatment value with no significant difference between the groups despite the patients with two cycles showing higher mean values for all the scores. Intra-articular PRP injections into the knee for symptomatic early stages of $\mathrm{OA}$ are a valid treatment option.

And he concluded that there is a significant reduction in pain and improvement in function after 12 months, which can be further improved at 18 months by annual repetition of the treatment. Although the beneficial effects are ill sustained at 2 years, the results are encouraging when compared to the pretreatment function. A systematic review of the effects of platelet rich plasma on outcomes for patients with knee osteoarthritis and following total knee arthroplasty [111].

A total of 2328 participants were analyzed across 17 included studies and pooled results showed a statistically significant reduction in pain in favor of PRP following TKA but not in non-surgical management of knee OA $(P<0.0001$ and 0.13 respectively).

No clinical benefit of PRP was found on quality of life and knee function ( $\mathrm{P}=0.07$ and 0.05$)$ following TKA, although a statistical improvement in knee function was demonstrated in patients with knee OA after PRP injection $(P<0.0001)$. There was no statistically significant clinical benefit of PRP on secondary outcomes including wound scores and length of hospital stay ( $p=0.33$ and 0.31 , respectively). There was no statistically significant difference in respect to blood loss and overall symptoms in favor of PRP compared to control group following TKA $(\mathrm{p}=0.37)$. This systematic review demonstrated no long-term statistically significant improvement in patient validated outcomes and secondary outcomes both in patients with knee OA or following TKA for $\mathrm{OA}^{[111]}$.

However PRP has been shown to have short to mediumtermbenefits in pain control after TKA and activities of daily living in patients with OA Combined intra-articular injections (Hyaluronic acid, platelet-rich plasma, and corticosteroid) for osteoarthritis knee, an effective alternative treatment [112] Sanjay Kumar Rai, Vasudevan P Raman, Rohit Varma, Sunit kumar S Wani from Department of Orthopaedics, Indian Naval Hospital Ship Asvini, Mumbai, Maharashtra, India Department of Orthopaedics, Malla Reddy Institute of Medical Sciences, Hyderabad, Telangana, India in august 2018 concluded by reviewing current literature and their own experience, they feel that IA injections of HA, PRP, and corticosteroids given together for knee $\mathrm{OA}$ are an effective 
nonoperative modality of treatment. In combination, they seem to have better efficacy than any of them given alone. These injections are clinically safe and have promising and very positive effects for patient satisfaction. When the heterogeneity of OA is considered, it is difficult to categorize which patients and what level of disease would be ideal indications for IA injections. Advanced or severe OA with significant deformity/radiological changes is less likely to benefit from this treatment stratagem. In our study, specific patient characteristics (parents of soldiers living in villages), symptoms and clinical findings (mild to moderately severe), and those reluctant or unwilling to undergo surgery may be indications for a practical/reasonable approach for IA injections, by which total knee replacement may be postponed or avoided. The addition of a steroid is reasonable in acute and persistent synovitis and gives faster relief in pain. Based on their study, they feel that a combination of IA injections (HA, PRP, and corticosteroid) for OA of the knee is an effective alternative treatment in patients with low-to-medium work demand and who are either unwilling or not yet candidates for total joint arthroplasty. ((Rai, Raman, Varma, \& Wani, 2018)

\section{Statistical Analysis}

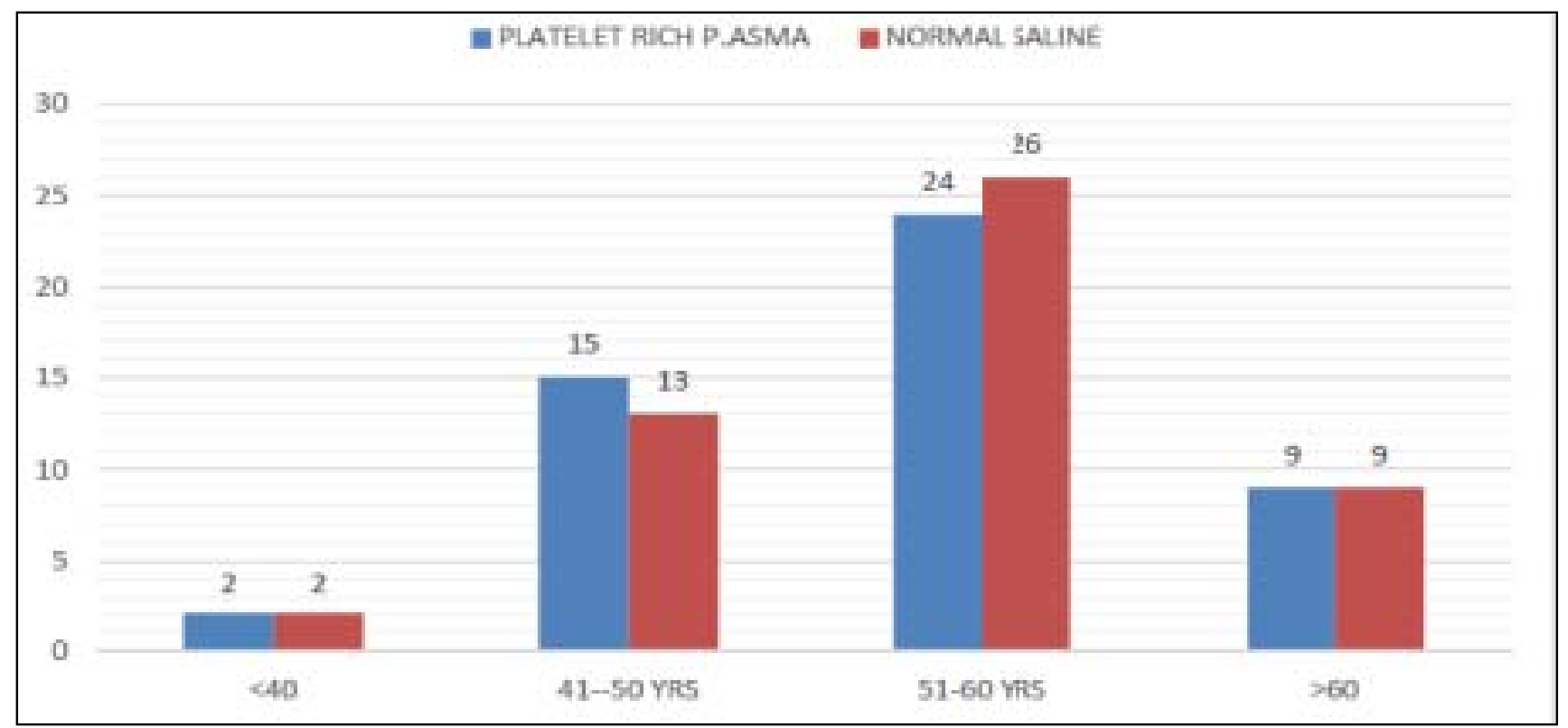

Fig 1: Age Distribution

\begin{tabular}{|l|c|c|c|c|}
\hline \multicolumn{1}{|c|}{ Age } & $\begin{array}{c}\text { Platelet Rich } \\
\text { Plasma }\end{array}$ & $\%$ & $\begin{array}{c}\text { Normal } \\
\text { Saline }\end{array}$ & $\%$ \\
\hline $\mathbf{5 0}$ years & 2 & 4.00 & 2 & 4.00 \\
\hline $\mathbf{4 1 - 5 0}$ years & 15 & 30.00 & 13 & 26.00 \\
\hline $\mathbf{5 1 - 6 0}$ years & 24 & 48.00 & 26 & 52.00 \\
\hline $\mathbf{7 6 0}$ years & 9 & 18.00 & 9 & 18.00 \\
\hline Total & 50 & 100 & 50 & 100 \\
\hline
\end{tabular}

\begin{tabular}{|l|c|c|}
\hline \multicolumn{1}{|c|}{ Age Distribution } & $\begin{array}{c}\text { Platelet Rich } \\
\text { Plasma }\end{array}$ & Normal Saline \\
\hline N & 50 & 50 \\
\hline Mean & 53.14 & 53.68 \\
\hline SD & 6.97 & 6.45 \\
\hline P value Unpaired t Test & \multicolumn{2}{|c|}{$\mathbf{0 . 6 8 8 5}$} \\
\hline
\end{tabular}




\section{Gender Distribution}

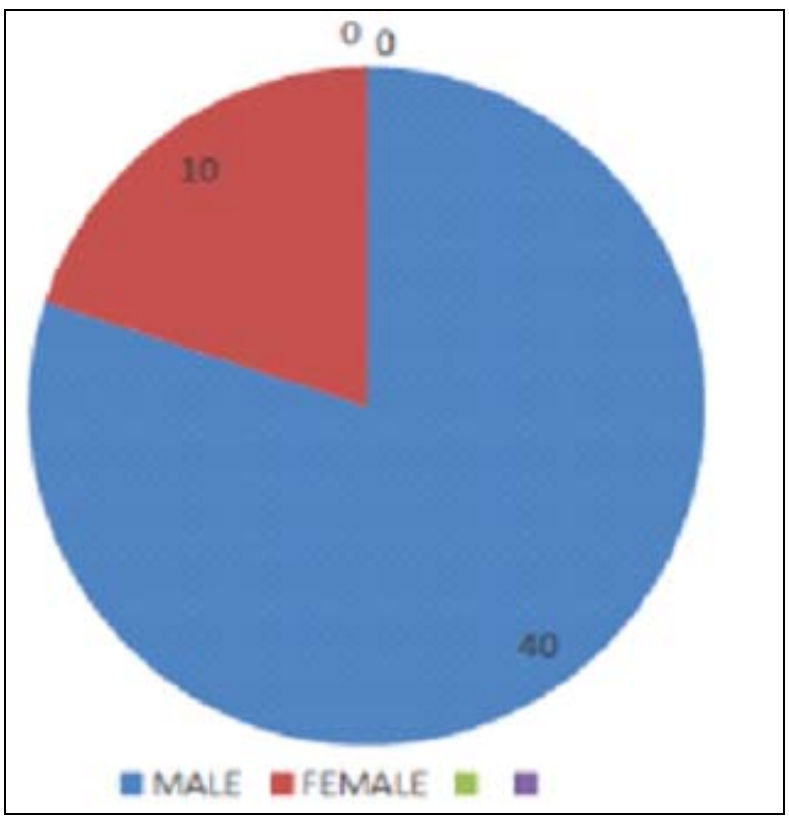

Fig 2: Gender Distribution

\begin{tabular}{|l|c|c|c|c|}
\hline $\begin{array}{c}\text { Gender } \\
\text { Distribution }\end{array}$ & $\begin{array}{c}\text { Platele } \\
\text { t Rich } \\
\text { Plasm }\end{array}$ & $\%$ & $\begin{array}{c}\text { Normal } \\
\text { Saline }\end{array}$ & $\%$ \\
\hline Male & 40 & 80.00 & 40 & 80.00 \\
\hline Female & 10 & 20.00 & 10 & 20.00 \\
\hline Total & 50 & 100 & 50 & 100 \\
\hline \multicolumn{2}{|l|}{ P values Chi Square Test } \\
\hline
\end{tabular}

\section{Height Distribution}

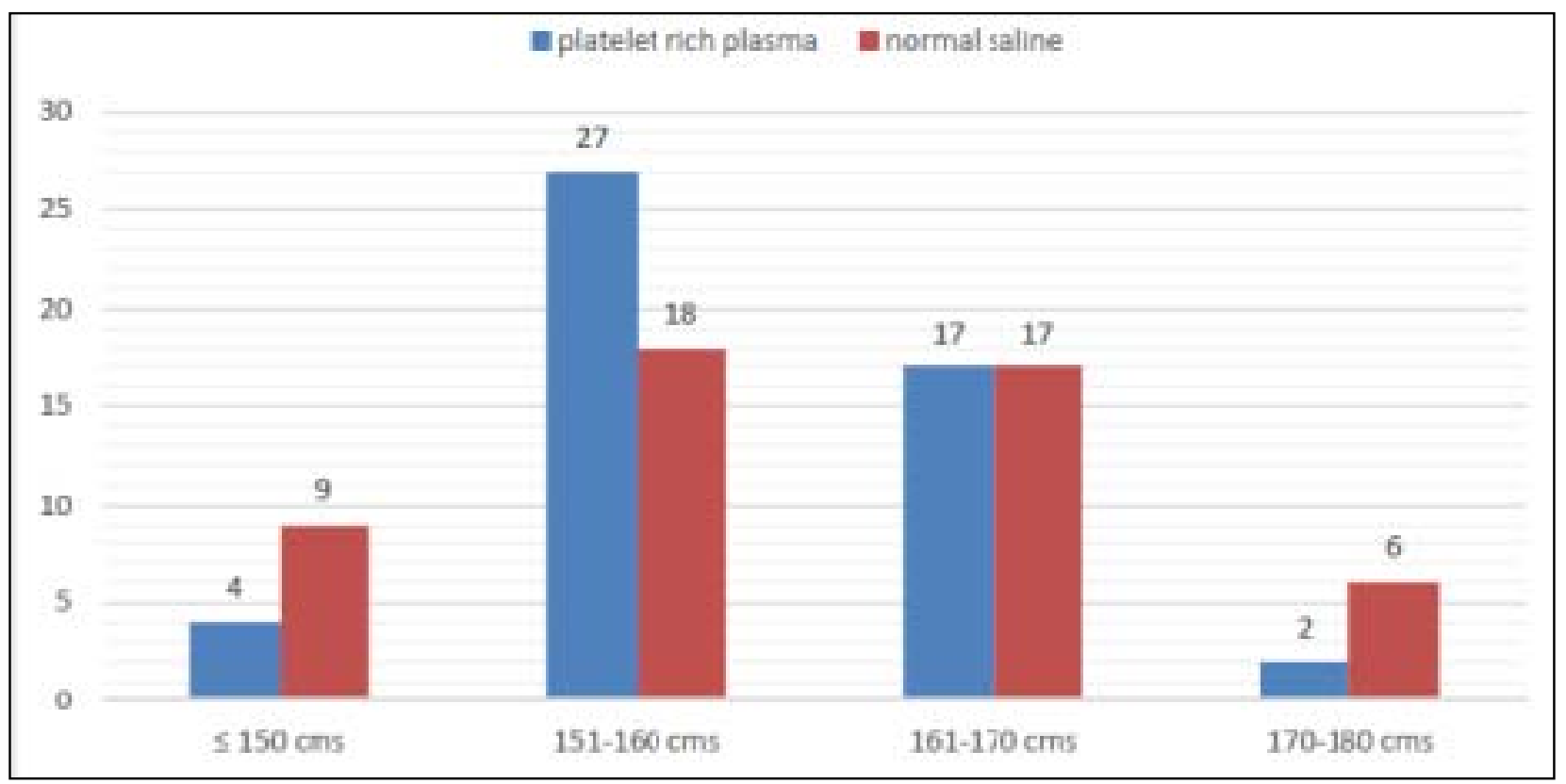

Fig 3: Height Distribution $\sim 948 \sim$ 


\begin{tabular}{|l|c|c|l|l|}
\hline $\begin{array}{l}\text { Height } \\
\text { Distribution }\end{array}$ & $\begin{array}{l}\text { Platelet } \\
\text { Rich } \\
\text { Plasma }\end{array}$ & $\%$ & $\begin{array}{l}\text { Normal } \\
\text { Saline }\end{array}$ & \multicolumn{2}{l|}{} \\
\hline $\mathbf{S 1 5 0} \mathbf{c m s}$ & 4 & 8.00 & 9 & 18.00 \\
\hline $\mathbf{1 5 1 - 1 6 0} \mathbf{c m s}$ & 27 & 54.00 & 18 & 36.00 \\
\hline $\mathbf{1 6 1 - 1 7 0} \mathbf{c m s}$ & 17 & 34.00 & 17 & 34.00 \\
\hline $\mathbf{1 7 0 - 1 8 0} \mathbf{c m s}$ & 2 & 4.00 & 6 & 12.00 \\
\hline Total & 50 & 100 & 50 & 100 \\
\hline
\end{tabular}

\begin{tabular}{|l|c|c|}
\hline Height Distribution & $\begin{array}{l}\text { Platelet Rich } \\
\text { Plasma }\end{array}$ & Normal Saline \\
\hline N & 50 & 50 \\
\hline Mean & 159.66 & 159.68 \\
\hline SD & 6.63 & 8.39 \\
\hline P value Unpaired t Test & \multicolumn{2}{|c|}{$\mathbf{0 . 9 8 9 5}$}
\end{tabular}

Weight Distribution

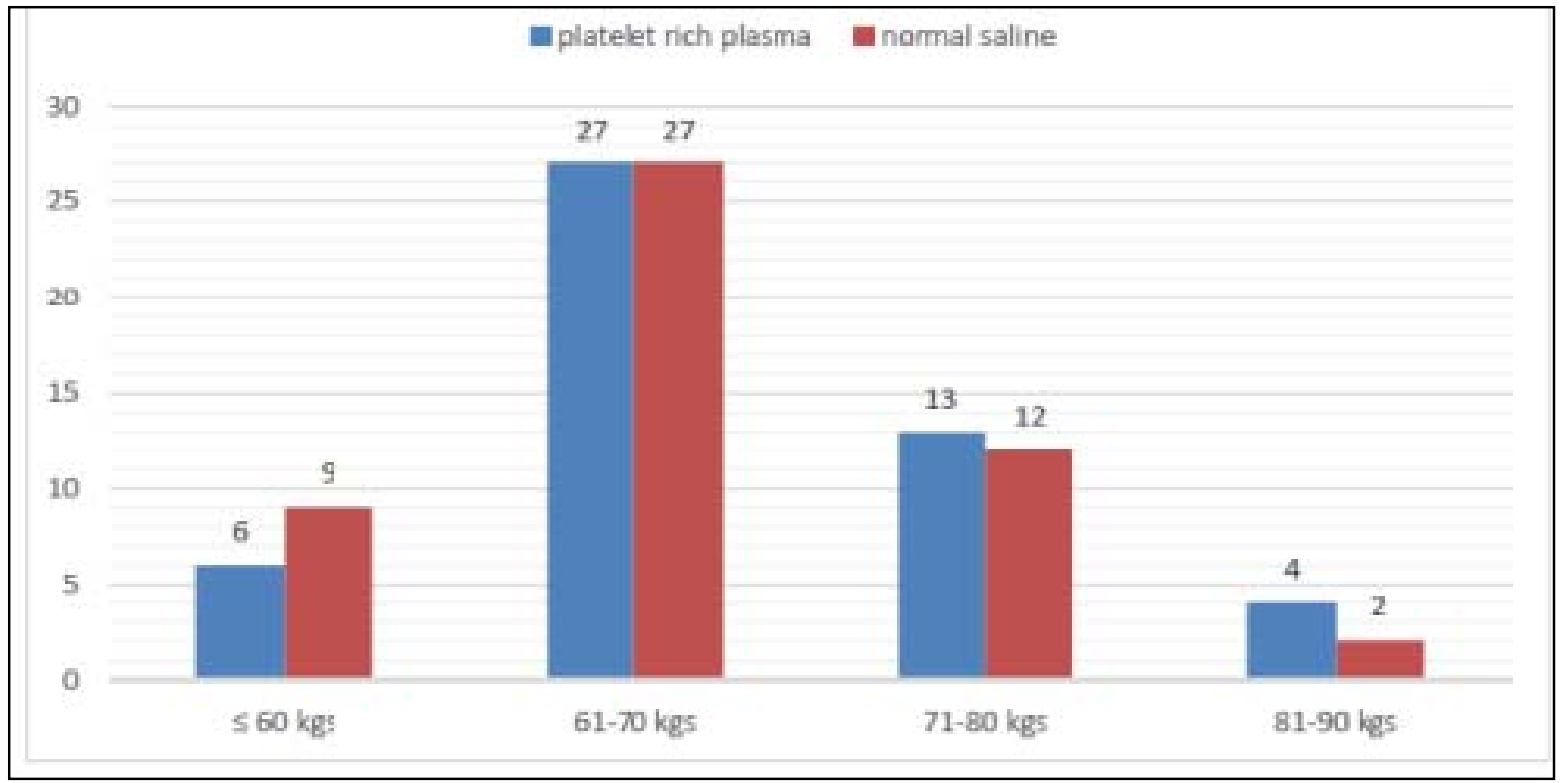

Fig 4: Weight Score

\begin{tabular}{|l|c|c|c|c|}
\hline \hline $\begin{array}{l}\text { Weight } \\
\text { Distribution }\end{array}$ & $\begin{array}{l}\text { Platele } \\
\text { t Rich } \\
\text { Plasma }\end{array}$ & $\%$ & $\begin{array}{c}\text { Normal } \\
\text { Saline }\end{array}$ & $\%$ \\
\hline$\leq 60 \mathrm{kgs}$ & 6 & 12.00 & 9 & 18.00 \\
\hline $\mathbf{6 1 - 7 0} \mathbf{k g s}$ & 27 & 54.00 & 27 & 54.00 \\
\hline $\mathbf{7 1 - 8 0}$ kgs & 13 & 26.00 & 12 & 24.00 \\
\hline $\mathbf{8 1 - 9 0}$ kgs & 4 & 8.00 & 2 & 4.00 \\
\hline Total & 50 & 100 & 50 & 100 \\
\hline
\end{tabular}




\begin{tabular}{|l|c|c|}
\hline Weight Distribution & $\begin{array}{c}\text { Platelet Rich } \\
\text { Plasma }\end{array}$ & Normal Saline \\
\hline N & 50 & 50 \\
\hline Mean & 68.62 & 67.66 \\
\hline SD & 6.84 & 6.63 \\
\hline P value Unpaired t Test & \multicolumn{2}{|c|}{$\mathbf{0 . 4 7 7 7}$} \\
\hline
\end{tabular}

BMI Distribution

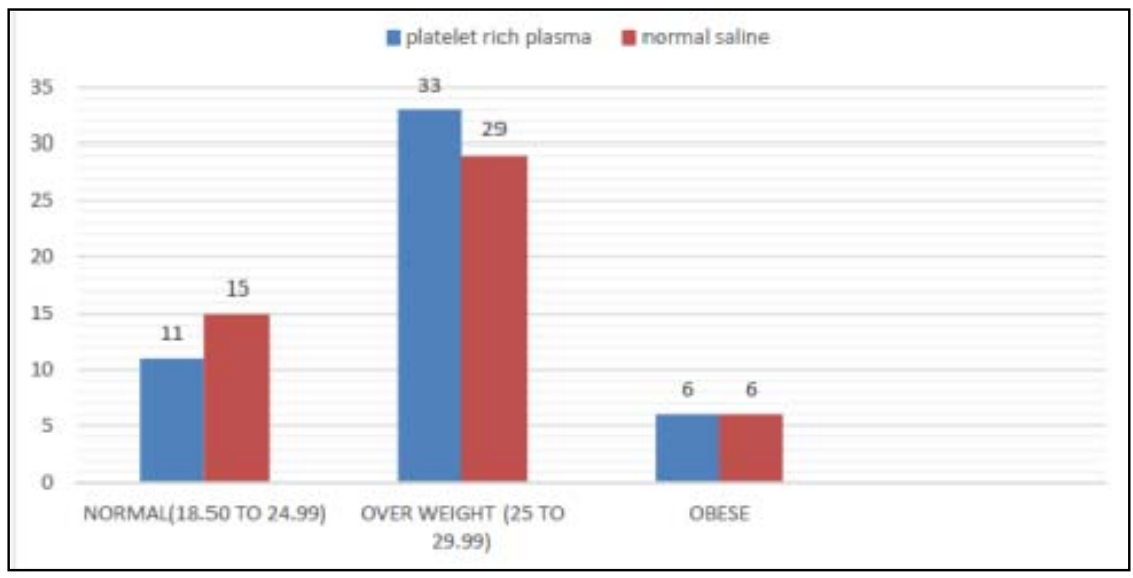

Fig 5: BMI Score

\begin{tabular}{|l|c|c|c|c|}
\hline BMI Distribution & $\begin{array}{c}\text { Platelet } \\
\text { Rich } \\
\text { Plasma }\end{array}$ & $\%$ & $\begin{array}{c}\text { Normal } \\
\text { Saline }\end{array}$ & $\%$ \\
\hline Underweight (⒙49) & 0 & 0.00 & 0 & 0.00 \\
\hline Normal (18.50 to 24.99) & 11 & 22.00 & 15 & 30.00 \\
\hline Overweight (25 to 29.99) & 33 & 66.00 & 29 & 58.00 \\
\hline Obese & 6 & 12.00 & 6 & 12.00 \\
\hline Total & 50 & 100 & 50 & 100 \\
\hline
\end{tabular}

\begin{tabular}{|l|c|c|}
\hline BMI Distribution & $\begin{array}{c}\text { Platelet Rich } \\
\text { Plasma }\end{array}$ & Normal Saline \\
\hline N & 50 & 50 \\
\hline Mean & 26.97 & 26.64 \\
\hline SD & 2.70 & 2.92 \\
\hline P value Unpaired t Test & \multicolumn{2}{|c|}{$\mathbf{0 . 5 5 0 7}$} \\
\hline
\end{tabular}

WOMAC Score

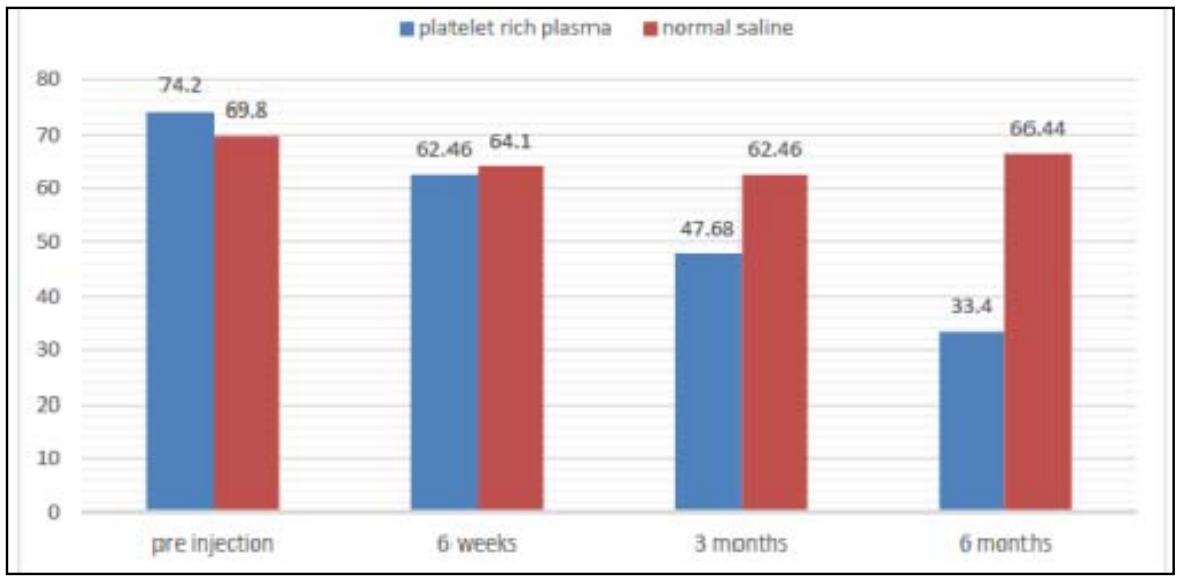

Fig 6: WOMAC Score

950 


\begin{tabular}{|l|l|l|l|l|l|}
\hline \multirow{2}{*}{ WOMAC Score } & Preinjection & $\begin{array}{l}\mathbf{6} \\
\text { weeks }\end{array}$ & $\begin{array}{l}\mathbf{3} \\
\text { mont } \\
\text { hs }\end{array}$ & $\begin{array}{l}\mathbf{6} \\
\text { mont } \\
\text { hs }\end{array}$ \\
\hline \multirow{2}{*}{$\begin{array}{l}\text { PlateletRich } \\
\text { Plasma }\end{array}$} & $\mathrm{N}$ & 50 & 50 & 50 & 50 \\
\cline { 2 - 6 } & Mean & 74.20 & 62.46 & 47.68 & 33.40 \\
\cline { 2 - 6 } & SD & 4.85 & 6.60 & 8.15 & 7.59 \\
\hline \multirow{2}{*}{\begin{tabular}{l} 
Normal Saline \\
\cline { 2 - 6 }
\end{tabular}} & Mean & 50 & 50 & 50 & 50 \\
\cline { 2 - 6 } & SD & 4.68 & 64.10 & 62.46 & 66.44 \\
\hline P value Unpaired t Test & $\mathbf{0 . 1 8 0 4}$ & 5.50 & 5.44 & 5.01 \\
\hline
\end{tabular}

\section{PAIN Score}

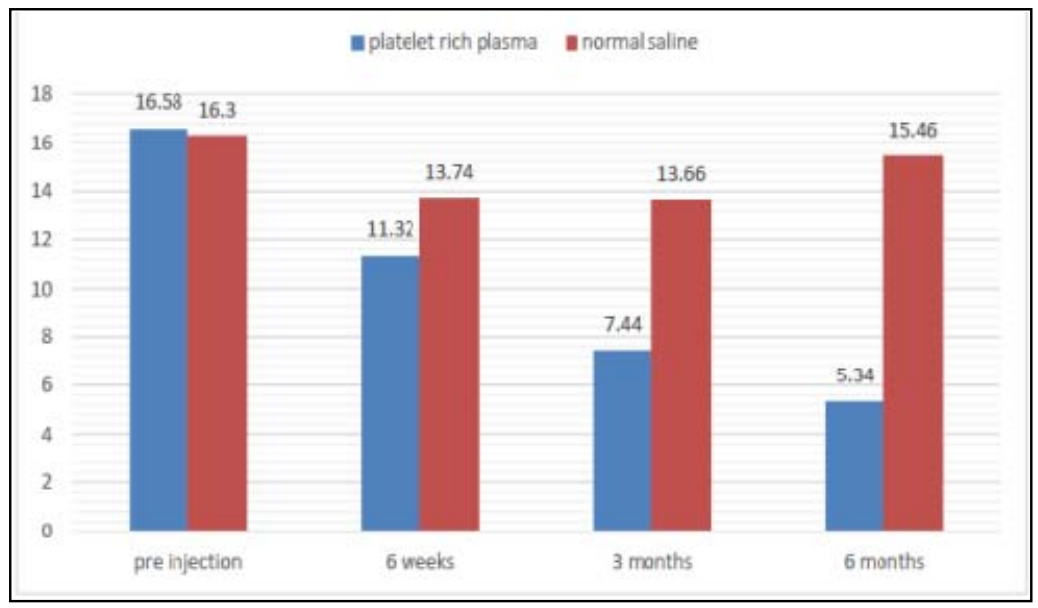

Fig 7: Pain Score

\begin{tabular}{|l|l|l|l|l|l|}
\hline \multicolumn{2}{|l|}{ Pain Score } & Pre injection & $\mathbf{6}$ weeks & $\begin{array}{l}\mathbf{3} \\
\text { months }\end{array}$ & $\begin{array}{l}\mathbf{6} \\
\text { months }\end{array}$ \\
\hline \multirow{2}{*}{$\begin{array}{l}\text { Platelet Rich } \\
\text { Plasma }\end{array}$} & $\mathrm{N}$ & 50 & 50 & 50 & 50 \\
\cline { 2 - 6 } & Mean & 16.58 & 11.32 & 7.44 & 5.34 \\
\cline { 2 - 6 } & $\mathrm{SD}$ & 3.08 & 2.76 & 1.93 & 1.42 \\
\hline \multirow{3}{*}{\begin{tabular}{l} 
Normal Saline \\
\cline { 2 - 6 }
\end{tabular}} & $\mathrm{N}$ & 50 & 50 & 50 & 50 \\
\cline { 2 - 7 } & Mean & 16.30 & 13.74 & 13.66 & 15.46 \\
\hline \multicolumn{2}{|l|}{ P value Unpaired Test } & 2.39 & 2.28 & 2.35 & 1.94 \\
\hline
\end{tabular}

\section{Stiffness Score}

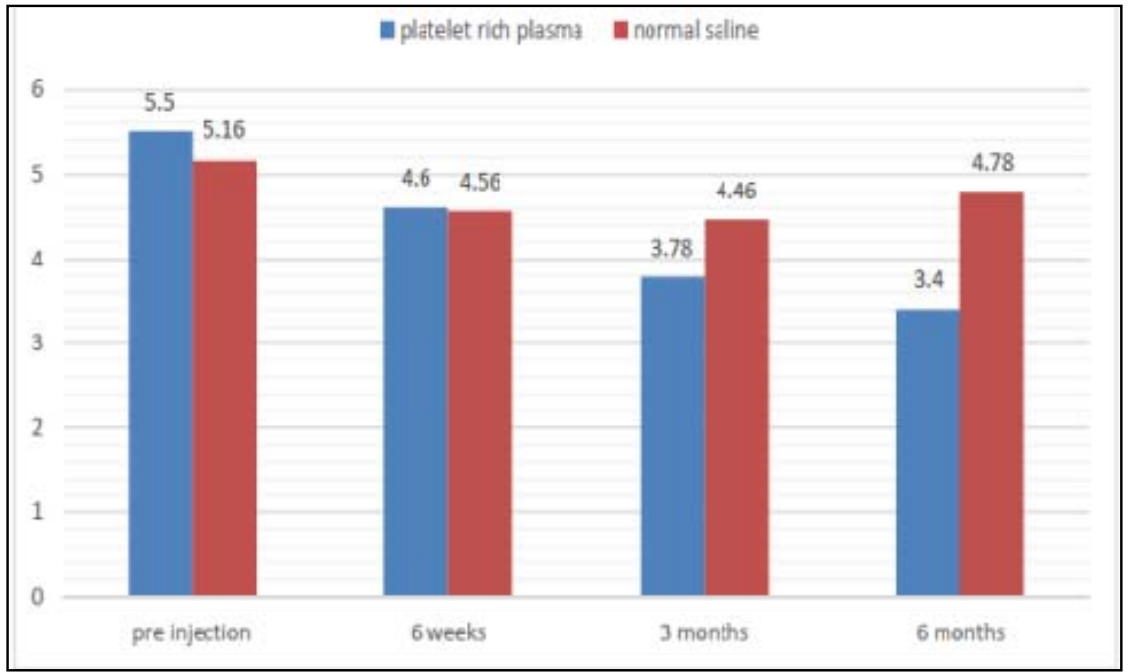

Fig 8: Stiffness Score $\sim 951 \sim$ 


\begin{tabular}{|l|l|l|l|l|l|}
\hline \multirow{2}{*}{ Stiffness Score } & Pre injection & $\mathbf{6}$ & $\mathbf{3}$ & $\mathbf{6}$ \\
& weeks & months & months \\
\hline \multirow{2}{*}{$\begin{array}{l}\text { Platelet Rich } \\
\text { Plasma }\end{array}$} & N & 50 & 50 & 50 & 50 \\
\cline { 2 - 6 } & Mean & 5.50 & 4.60 & 3.78 & 3.40 \\
\cline { 2 - 6 } & SD & 1.22 & 1.20 & 1.09 & 1.14 \\
\hline \multirow{3}{*}{ Normal Saline } & $\mathrm{N}$ & 50 & 50 & 50 & 50 \\
\cline { 2 - 6 } & Mean & 5.16 & 4.56 & 4.46 & 4.78 \\
\cline { 2 - 6 } & SD & 0.93 & 0.81 & 0.73 & 0.84 \\
\hline P value Unpaired t Test & $\mathbf{0 . 1 2 0 4}$ & $\mathbf{0 . 8 4 5 3}$ & $\mathbf{0 . 0 0 0 4}$ & $\mathbf{0 . 0 0 0 2}$ \\
\hline
\end{tabular}

Physical Function Score

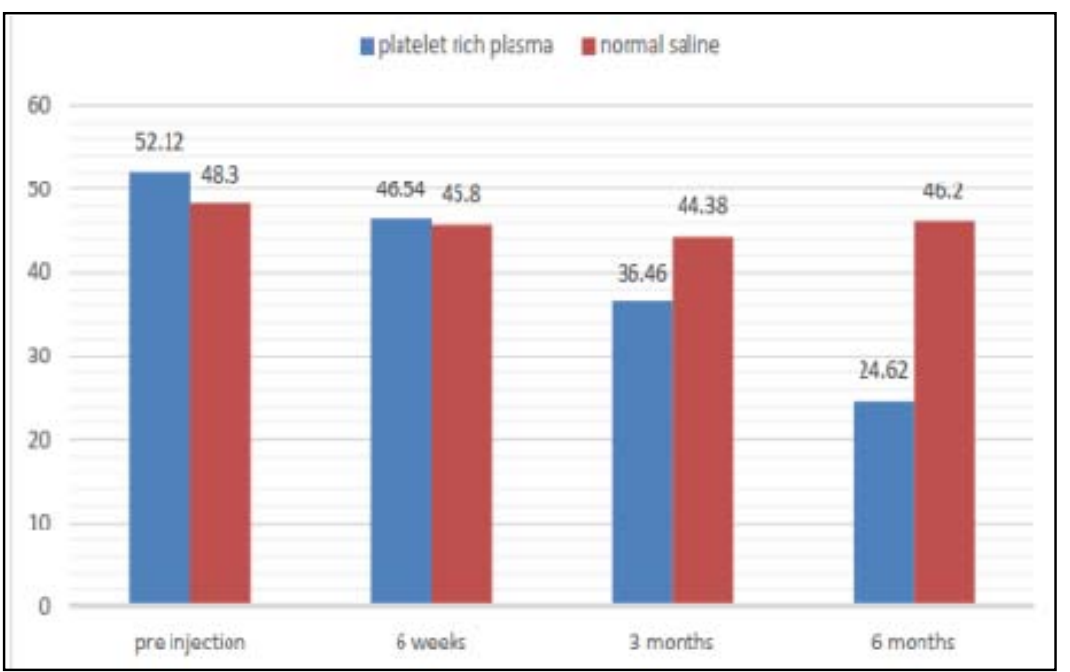

Fig 9: Physical Functional Score

\begin{tabular}{|l|l|l|l|l|l|}
\hline \multicolumn{2}{|l|}{ Physical Function Score } & Pre injection & $\begin{array}{l}\mathbf{6} \\
\text { weeks }\end{array}$ & $\begin{array}{l}\mathbf{3} \\
\text { month }\end{array}$ & $\begin{array}{l}\mathbf{6} \\
\text { month }\end{array}$ \\
\hline \multirow{2}{*}{$\begin{array}{l}\text { Platelet Rich } \\
\text { Plasma }\end{array}$} & $\mathrm{N}$ & 50 & 50 & 50 & 50 \\
\cline { 2 - 6 } & Mean & 52.12 & 46.54 & 36.46 & 24.62 \\
\cline { 2 - 6 } & SD & 3.77 & 4.53 & 6.49 & 6.33 \\
\hline \multirow{2}{*}{$\begin{array}{l}\text { Normal } \\
\text { Saline }\end{array}$} & $\mathrm{N}$ & 50 & 50 & 50 & 50 \\
\cline { 2 - 6 } & Mean & 48.30 & 45.80 & 44.38 & 46.20 \\
\cline { 2 - 6 } & SD & 3.17 & 3.91 & 3.88 & 3.67 \\
\hline P value Unpaired t Test & $\mathbf{0 . 3 8 4 0}$ & & & 0.2885 \\
\hline
\end{tabular}

Visual Analog Score

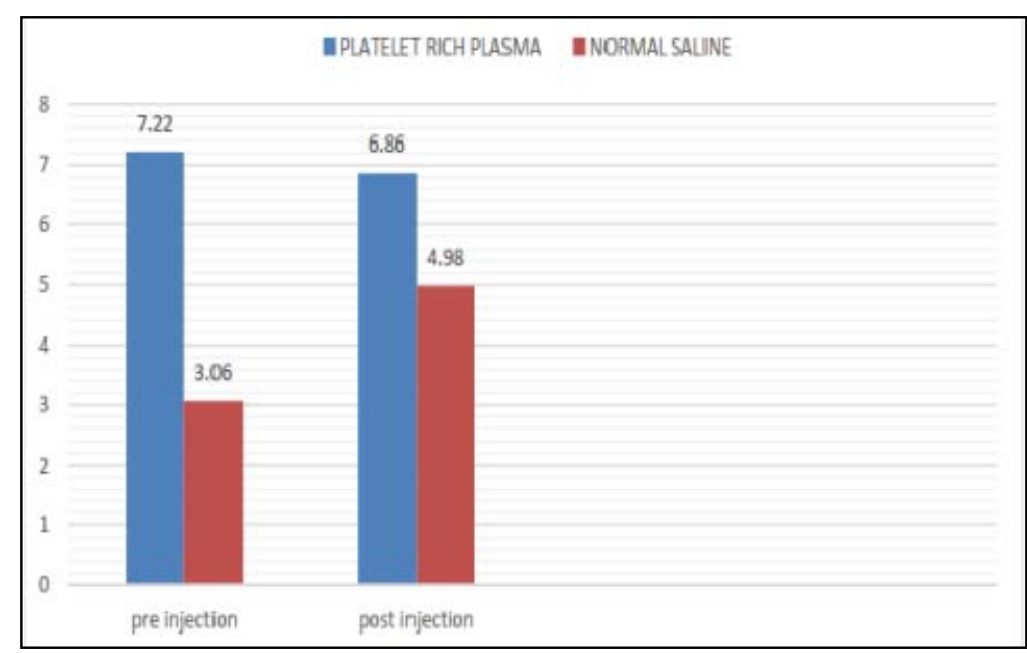

Fig 10: Visual analog score 952 


\begin{tabular}{|l|c|c|c|}
\hline \multicolumn{2}{|l|}{ Visual Analog Score } & Pre injection & Post injection \\
\hline \multirow{2}{*}{$\begin{array}{l}\text { Platelet Rich } \\
\text { Plasma }\end{array}$} & $\mathrm{N}$ & 50 & 50 \\
\cline { 2 - 4 } & Mean & 7.22 & 3.06 \\
\cline { 2 - 4 } & SD & 0.97 & 1.24 \\
\hline \multirow{3}{*}{ Normal Saline } & $\mathrm{N}$ & 50 & 50 \\
\cline { 2 - 4 } & Mean & 6.86 & 4.98 \\
\cline { 2 - 4 } & SD & 0.81 & 0.89 \\
\hline \multicolumn{2}{|c|}{ P value Unpaired t Test } & $\mathbf{0 . 0 4 7 3}$ & $\mathbf{0 . 0 0 0 0}$ \\
\hline
\end{tabular}

\section{Conclusion}

The Epidemic of Modernization coupled with effective health care delivery has led to an expanded lifespan of human beings. The focus of health care providers is undergoing a drift towards non communicable and degenerative disorders. Osteoarthritis represents a failure of diarthrodial joint, characterized by degenerative changes in articular cartilage of joint. The management of Osteoarthritis has undergone a sea change during the last century. Osteoarthritis has been managed by conservative methods like lifestyle changes, physiotherapy and surgical methods like joint replacement arthroplasty, depending upon the stage of the disorder. A constant search for molecules that could aid in cartilage regeneration, thus interfering in disease process has thrown up surprises. One such ideology is, garnering the beneficial effect of growth factors in platelets to regenerate cartilage in a synovial joint. Our study relied on injecting a highly concentrated mix of platelets into joint cavity and observing the patients for reduction in symptoms of pain, stiffness and improvement in physical function. Our study has revealed a consistent reduction in pain and stiffness and a clear improvement in lifestyle of the patients.

Our study has thrown up an interesting choice of treatment modality

using Platelet Rich Plasma in the treatment of Knee Osteoarthritis and it

has proved efficacious in the observation period of six months.

\section{References}

1. Hadler NM. Knee pain is the malady--not osteoarthritis. Ann Intern Med. 1992; 116:598-9. [PubMed]

2. Ayis S, Dieppe P. The natural history of disability and its determinants in adults with lower limb musculoskeletal pain. J Rheumatol. 2009; 36:583-91. [PubMed]

3. Silman AJ, Hochberg MC. $2^{\text {nd }}$ ed. Oxford: Oxford University Press, 2001. Epidemiology of the Rheumatic Diseases.

4. Symmons D, Mathers C, Pfleger B. Global Burden of Osteoarthritis in year 2000: Global burden of disease 2000 study. World health report. 2002; 5 (2).

5. Grynpas MD, Alpert B, Katz I, Lieberman I, Pritzker KP. Subchondral bone in osteoarthritis. Calcif Tissue Int 1991; 15:20-26. doi: 10.1007/BF02555898.[PubMed] [Cross Ref]

6. Solomon LD. Warwick, Nayagam S. Apley's system of orthopaedics and fractures, 9th ed., CRC press, 2010. View Book

7. Louis Solomon, David Warwick, Selvadurai Nayagam2010 - Medical87 58855.5 Osteoarthritis - pathology.

8. Buckwalter JA, Roughley PJ, Rosenberg LC. Age-related changes in cartilage proteoglycans: quantitative electron microscopic studies. Microscopy Research and Technique. 1994; 28(5):398-408. [PubMed]
9. Bolton MC, Dudhia J, Bayliss MT. Age-related changes in the synthesis of link protein and aggrecan in human articular cartilage: implications for aggregate stability. Biochemical Journal. 1999; 337(part 1):77-82. [PMC free article] [PubMed]

10. Bellamy NMD, MSC, FRCP (Glas), FRCP (Edin), FRCP(C), FACP. 1997; 11(4)-657-840.

11. Haslauer CM, Elsaid KA, Fleming BC, Proffen BL, Johnson VM, Murray MM. Loss of extracellular matrix from articular cartilage is mediated by the synovium and ligament after anterior cruciate ligament injury. Osteoarthritis Cartilage. 2013; 21:1950-1957. [PMC free article] [PubMed]

12. Jackson MT, Moradi B, Zaki S, Smith MM, McCracken $\mathrm{S}$, Smith SM, et al. Depletion of protease-activated receptor 2 but not protease-activated receptor 1 may confer protection against osteoarthritis in mice through extra cartilaginous mechanisms. Arthritis Rheumatol. 2014; 66:3337-3348. [PubMed]

13. Louis Solomon, David Warwick, Selvadurai Nayagam Preview More editions5.5 Osteoarthritis. 2010.

14. Jiang L, Rong J, Wang Y, Hu F, Bao C, Li X et al. The relationship between body mass index and hip osteoarthritis: a systematic review and metaanalysis. Joint Bone Spine. 2011; 78:150-5. [PubMed]

15. Jiang L, Tian W, Wang Y, Rong J, Bao C, Liu Y, et al. Body mass index and susceptibility to knee osteoarthritis: a systematic review and metaanalysis. Joint Bone Spine. 2012; 79:291-7. [PubMed]

16. Anderson J, Felson DT: Factors associated with osteoarthritis of the knee in the First National Health and Nutrition Examination (HANES I). Am. J. Epidemiol. 1988; 128:179-189.

17. Aggarwal T, Bhatia RC, Singh D, Sobti PC. Prevalence of obesity and overweight in affluent adolescents from Ludhiana, Punjab. Indian Pediatr. 2008; 45:500-2. [PubMed]

18. Dieppe P, Cushnaghan J, Jasani MK, McCrae F, Watt I. A two-year, placebo-controlled trial of nonsteroidal antiinflammatory therapy in osteoarthritis of the knee joint. Br J Rheumatol. 1993; 32(7):595-600.

19. Swann DA, Radin EL. The molecular basis of articular lubrication. I. Purification and properties of a lubricating fraction from bovine synovial fluid. J. Biol. Chem.1972; 247:8069-8073. [PubMed]

20. Jay GD, Haberstroh K, Cha CJ. Comparison of the boundary-lubricating ability of bovine synovial fluid, lubricin, and Healon. J. Biomed. Mater. Res. 1998; 40:414-418. [PubMed]

21. Jay GD. Characterization of a bovine synovial fluid lubricating factor. I. Chemical, surface activity and lubricating properties. Connect. Tissue Res. 1992; 28:7188. [PubMed]

22. Jay GD, Britt DE, Cha CJ. Lubricin is a product of 
megakaryocyte stimulating factor gene expression by human synovial fibroblasts. J Rheumatol. 2000; 27:594600. [PubMed]

23. Benito MJ, Veale DJ, Fitz Gerald O, van den Berg WB, Bresnihan B. Synovial tissue inflammation in early and late osteoarthritis. Ann Rheum Dis. 2005; 64:1263-7. [PMC free article] [PubMed]

24. RF Loeser et al: Arthritis Rheum. (harrisons principles of internal medicine 20th edition chap 364) (C) 2018 American College of Rheumatology. Used with permission.). 2012; 64:1697.

25. James SL. Surgical Anatomy of the Knee. In: Schulitz KP., Krahl H., Stein W.H. (eds) Late Reconstructions of Injured Ligaments of the Knee. Springer, Berlin, Heidelberg, 1978.

26. Conley CL. Hemostasis. In: Mountcastle VB, editor. Medical Physiology. St. Louis: The C.V. Mosby Company; 2004, 1137-46.

27. Harrison P, Cramer EM. Platelet alpha-granules. Blood Rev. 1993; 7:52-62. [PubMed]

28. Schliephake H. Bone growth factors in maxillofacial skeletal reconstruction. Int. J Oral Maxillofac Surg. 2002; 31:469-84. [PubMed]

29. Sunitha Raja V, Munirathnam Naidu E. Platelet-rich fibrin: Evolution of a second-generation platelet concentrate. Indian J Dent Res. 2008; 19:42-6. [PubMed]

30. Cole BJ, Seroyer ST, Filardo G, Bajaj S, Fortier LA. Platelet-rich plasma: Where are we now and where are we going? Sports Health. 2010; 2:203-10. [PMC free article] [PubMed]

31. Kevy SV, Jacobson MS. Comparison of methods for point of care preparation of autologous platelet gel. J Extra Corpor Technol. 2004; 36:28-35. [PubMed]

32. Marx RE. Platelet-rich plasma: Evidence to support its use. J Oral Maxillofac Surg. 2004; 62:489-96. [PubMed]

33. Antoniades HN, Williams LT. Human platelet-derived growth factor: Structure and functions. Fed Proc. 1983; 42:2630-4. [PubMed]

34. Marx RE. Platelet-Rich Plasma (PRP): What Is PRP and What Is Not PRP? Implant Dent. 2001; 10:225-8. [PubMed]

35. Rughetti A, Giusti I, D'Ascenzo S, Leocata P, Carta G, Pavan A, et al. Platelet gel-released supernatant modulates the angiogenic capability of human endothelial cells. Blood Transfus. 2008; 6:12-7. [PMC free article] [PubMed]

36. Dohan Ehrenfest DM, Rasmusson L, Albrektsson T. Classification of platelet concentrates: From pure platelet-rich plasma (P-PRP) to leucocyte-and plateletrich fibrin (L-PRF) Trends Biotechnol. 2009; 27:158-67. [PubMed

37. Dohan Ehrenfest DM, Bielecki T, Mishra A, Borzini P, Inchingolo $\mathrm{F}$, Sammartino $\mathrm{G}$, et al. In search of a consensus terminology in the field of platelet concentrates for surgical use: Platelet-rich plasma (PRP), plateletrich fibrin (PRF), fibrin gel polymerization and leukocytes. Curr Pharm Biotechnol. 2012; 13:1131-7. [PubMed]

38. Sweeny J, Grossman BJ. Blood collection, storage and component preparation methods. In: Brecher $\mathrm{M}$, editor. Technical Manual. 14th ed. Bethesda MD: American Association of Blood Banks (AABB); 2002. pp. 955-8.

39. Welsh WJ. Autologous platelet gel: Clinical function and usage in plastic surgery. Cosmetic Derm. 2000; 11:13-9.

40. Han B, Woodell-May J, Ponticiello M, Yang Z, Nimni
M. The effect of thrombin activation of platelet-rich plasma on demineralized bone matrix osteo inductivity. J Bone Joint Surg Am. 2009; 91:1459-70. [PubMed]

41. Kahn RA, Cossette I, Friedman LI. Optimum centrifugation conditions for the preparation of platelet and plasma products. Transfusion. 1976; 16:162-5. [PubMed]

42. Slichter SJ, Harker LA. Preparation and storage of platelet concentrates. I. Factors influencing the harvest of viable platelets from whole blood. Br J Haematol. 1976; 34:395-402. [PubMed]

43. Landesberg R, Roy M, Glickman RS. Quantification of growth factor levels using a simplified method of platelet-rich plasma gel preparation. J Oral Maxillofac Surg. 2000; 58:297-301. [PubMed]

44. Bausset O, Giraudo L, Veran J, Magalon J, Coudreuse $\mathrm{JM}$, Magalon $\mathrm{G}$, et al. Formulation and storage of platelet-rich plasma homemade product. Biores Open Access. 2012; 1:115-23. [PMC free article] [PubMed]

45. Montalvo S, Tresguerres I, Tamini FM, Blanco Jerez L. A comparative study of 2 methods for obtaining platelet rich plasma. J Oral Maxillofac Surg. 2007; 65:1084-93. [PubMed]

46. Mazzocca AD, McCarthy MB, Chowaniec DM, Cote MP, Romeo AA, Bradley JP, et al. Plateletrich plasma differs according to preparation method and human variability. J Bone Joint Surg Am. 2012; 94:308-16. [PubMed]

47. Anitua E, Aguirre JJ, Algorta J, Ayerdi E, Cabezas AI, Orive $\mathrm{G}$, et al. Effectiveness of autologous preparation rich in growth factors for the treatment of chronic cutaneous ulcers. J Biomed Mater Res B Appl Biomater. 2008; 84:415-21. [PubMed]

48. Circulating levels of IL- 6 and TNF- $\alpha$ are associated with knee radiographic osteoarthritis and knee cartilage loss in older adults. Stannus O, Jones G, Cicuttini F, Parameswaran V, Quinn S, Burgess J, Ding C Osteoarthritis Cartilage. 2010; 18(11):1441-7. [PubMed] [Ref list] Sellam J, Berenbaum F. The role of synovitis in pathophysiology and clinical symptoms of osteoarthritis. Nature Reviews Rheumatology. 2010; 6:625635.[PubMed]

49. Literature Review in Rheumatic Disease Clinics of North America 25(2):269-82. June 1999 with 12 Reads DOI: 10.1016/S0889857X(05)70067-3 · Source:PubMed

50. Wei LC, Lei GH, Sheng PY, et al. Efficacy of plateletrich plasma combined with allograft bone in the management of displaced intra-articular calcaneal fractures: a prospective cohort study. J Orthop Res 2012; 30:1570-6. [PubMed]

51. Patel S, Dhillon MS, Aggarwal S, et al. Treatment with platelet-rich plasma is more effective than placebo for knee osteoarthritis: a prospective, doubleblind, randomized trial. Am J Sports Med 2013; 41:356-64. [PubMed]

52. Dragoo JL, Wasterlain AS, Braun HJ, et al. Platelet-rich plasma as a treatment for patellar tendinopathy: a doubleblind, randomized controlled trial. Am J Sports Med. 2014; 42:610-8. [PubMed]

53. Molloy T, Wang Y, Murrell G. The roles of growth factors in tendon and ligament healing. Sports Med 2003; 33:381-94. [PubMed]

54. Article first published online: January 8, 2013; Issue published: February 1, 2013 Sandeep Patel, MS*, Mandeep S. Dhillon, MS, FAMS*†, Sameer Aggarwal*, 
Neelam Marwaha, MD, FAMS $\ddagger$, Ashish Jain, MD *Department of Orthopaedics, Post Graduate Institute of Medical Education and Research, Chandigarh, India \$Department of Transfusion Medicine, Post Graduate Institute of Medical Education and Research, Chandigarh, India. 2013; 41(2):356-364.

55. Khoshbin A1, Leroux $\mathrm{T}$, Wasserstein $\mathrm{D}$, Marks $\mathrm{P}$, Theodoropoulos J, Ogilvie-Harris D, Gandhi R, Takhar K, Lum G, Chahal J. The efficacy of platelet-rich plasma in the treatment of symptomatic knee osteoarthritis: a systematic review with quantitative synthesis. Arthroscopy. 2013; 29(12):2037-48.

DOI: $10.1016 /$ j.arthro.2013.09.006

56. Morteza Kalbkhani, Seifollah N. Dehghani, Alireza Najafpour, Naji S. Haddadi, Kalbkhani Mohamad Hossein. IBIMA Publishing Advances in Stem Cells http://www.ibimapublishing.com/ journals/ASC/asc.html 2014 (2014), Article ID 994022, 10 pages DOI: 10.5171/2014.994022 Copyright (C) 2014 Distributed under Creative Commons CC-BY 3.0

57. Filardo G1, Kon E, Buda R, Timoncini A, Di Martino A, Cenacchi A, Fornasari PM, Giannini S, Marcacci M. Knee Surg Sports Traumatol Arthrosc. 2011; 19(4):52835. doi: 10.1007/s00167-010-1238-6. Epub 2010 Aug 26. Platelet-rich plasma intraarticular knee injections for the treatment of degenerative cartilage lesions and osteoarthritis. PMID:20740273 DOI: 10.1007/s00167010-1238-6

58. Kon E, Buda R, Filardo G, Di Martino A, Timoncini A, Cenacchi A, Fornasari PM, Giannini S, Marcacci M. Platelet-rich plasma: intra-articular knee injections produced favorable results on degenerative cartilage lesions. Knee Surg Sports Traumatol Arthrosc. 2010; 18(4):472-9. [PubMed] [Ref list]

59. Sánchez M, Anitua E, Azofra J, Aguirre JJ, Andia I Clin Exp Rheumatol. Intra-articular injection of an autologous preparation rich in growth factors for the treatment of knee OA: a retrospective cohort study. 2008; 26(5):9103. [PubMed]

60. Infiltration of plasma rich in growth factors for osteoarthritis of the knee shortterm effects on function and quality of life. Wang-Saegusa A, Cugat R, Ares O, Seijas R, Cuscó X, Garcia-Balletbó March Orthop Trauma Surg. 2011; 131(3):311-7.[PubMed].

61. Filardo G, Kon E, Buda R, Timoncini A, Di Martino A, Cenacchi A, Fornasari PM, Giannini S, Marcacci M. Platelet-rich plasma intra-articular knee injections for the treatment of degenerative cartilage lesions and osteoarthritis. Knee Surg Sports Traumatol Arthrosc. 2011; 19(4):52835. [PubMed]Middle East Journal of Rehabilitation and Health: January 01. 2017; 4(1):e43200

62. Fernandez-Cuadros ME, Susana Perez-Moro O, Miróncanelo JA. Could ozone be used as a feasible future treatment in osteoarthritis of the knee?. 2016 Volume: 36 issue: 8 , page(s): 891-900 Article first published online: March 30, 2015; Issue published: August 1, 2015 Clinical Effects of Platelet-Rich Plasma and Hyaluronic Acid as an Additional Therapy for Talar Osteochondral Lesions Treated with Microfracture Surgery A Prospective Randomized Clinical Trial

63. Knee Surg Sports Traumatol Arthrosc. 2015; 23(8):21702177. doi: 10.1007/s00167-014-2987-4. Epub 2014 Apr 20. The effects of repeated intra-articular PRP injections on clinical outcomes of early osteoarthritis of the knee. Gobbi A1, Lad D2, Karnatzikos G2.
64. Forogh B, Mianehsaz E, Shoaee S, Ahadi T, Raissi GR, Sajadi S. J Sports Med Phys Fitness. 2016; 56(7-8):9018. Epub 2015 Jul 14.Effect of single injection of plateletrich plasma in comparison with corticosteroid on knee osteoarthritis: a double blind randomized clinical trial.

65. Petersson IF, Boegård $\mathrm{T}$, Saxne $\mathrm{T}$ et-al. Radiographic osteoarthritis of the knee classified by the Ahlbäck and Kellgren \& Lawrence systems for the tibiofemoral joint in people aged 35-54 years with chronic knee pain. Ann. Rheum. Dis. 1997; 56(8):493-6. doi:10.1136/ard.56.8.493 - Free text at pubmed - Pubmed citation

66. Kellgren JH, Lawrence JS. Radiological Assessment of Osteoarthrosis. Ann. Rheum. Dis. 2000; 16(4):494-502. Free text at Pubmed Pubmed Citation

67. Mark D. Kohn, Adam A. Sassoon, Navin D. Fernando. Classifications in Brief: Kellgren-Lawrence Classification of Osteoarthritis. Clinical Orthopaedics and Related Research ${ }^{\circledR}$. 2016; 474(8):1886. DOI: $10.1007 / \mathrm{s} 11999016-4732-4$ - Pubmed

68. Petersson IF, Boegård $\mathrm{T}$, Saxne $\mathrm{T}$ et al. Radiographic osteoarthritis of the knee classified by the Ahlbäck and Kellgren \& Lawrence systems for the tibiofemoral joint in people aged 35-54 years with chronic knee pain. Ann. Rheum. Dis. 1997; 56(8):493-6. DOI:10.1136/ard.56.8.493 - Free text at pubmed Pubmed citation

69. Journal ListOrthop J Sports Medv. 3(6); 2015 Jun PMC4622369 Orthop J Sports Med. 2015 Jun; 3(6): 2325967115588896. Published online 2015 Jun 23. doi: [10.1177/2325967115588896] PMCID: PMC4622369 PMID: 26665098Autologous Platelet-Rich Plasma Preparations Influence of Nonsteroidal Antiinflammatory Drugs on Platelet Function

70. Kon E, Mandelbaum B, Buda R, et al. Platelet-rich plasma intra- articular injection versus hyaluronic acid viscosupplementation as treatments for cartilage pathology: from early degeneration to osteoarthritis. Arthroscopy. 2011; 27:1490-501 (PDF) Considerations for the Use of Platelet-Rich Plasma in Orthopedics. Available from: https://www.researchgate.net/publication /261840156_Considerations_for_the_Use_of_PlateletRich_Plasma in_Orthopedics?

71. Filardo G, Kon E, Pereira Ruiz MT et al. Platelet-rich plasma intra-articular injections for cartilage degeneration and osteoar- thritis: single- versus doublespinning approach. Knee Surg Sports Traumatol Arthrosc. 2012; 20(10):2082-91.

72. http://www.womac.org 